\title{
The Financial Dialogue in the Development of Medical Treatment Plans
}

\author{
Christopher D. Busack, MS3 \\ Thomas Jefferson University, christopher.busack@jefferson.edu \\ Bethany Fox, MS3 \\ Sidney Kimmel Medical College at Thomas Jefferson University, bethany.fox@jefferson.edu
}

Follow this and additional works at: https://jdc.jefferson.edu/tmf

Part of the Health Economics Commons, and the Internal Medicine Commons

Let us know how access to this document benefits you

\section{Recommended Citation}

Busack, MS3, Christopher D. and Fox, MS3, Bethany (2016) "The Financial Dialogue in the Development of Medical Treatment Plans," The Medicine Forum: Vol. 17 , Article 20.

DOI: https://doi.org/10.29046/TMF.017.1.004

Available at: https://jdc.jefferson.edu/tmf/vol17/iss1/20

This Article is brought to you for free and open access by the Jefferson Digital Commons. The Jefferson Digital Commons is a service of Thomas Jefferson University's Center for Teaching and Learning (CTL). The Commons is a showcase for Jefferson books and journals, peer-reviewed scholarly publications, unique historical collections from the University archives, and teaching tools. The Jefferson Digital Commons allows researchers and interested readers anywhere in the world to learn about and keep up to date with Jefferson scholarship. This article has been accepted for inclusion in The Medicine Forum by an authorized administrator of the Jefferson Digital Commons. For more information, please contact: JeffersonDigitalCommons@jefferson.edu. 


\title{
The Financial Dialogue in the Development of Medical Treatment Plans
}

\author{
Christopher Busack, MS3, Bethany Fox, MS3
}

\begin{abstract}
As patients face increasingly high out-of-pocket costs and difficulties navigating the healthcare system, failing to discuss available treatment options in financial terms can lead to grave consequences for patients. Medical bills are responsible for the majority of bankruptcies in the United States. Given the severe financial implications of medical bills, it is imperative that patients become more involved in discussions of their treatment plans and become aware of the costs of their decisions up front. Counseling about costs ensures that physicians avoid placing a debilitating financial burden on patients and maintain adherence to the ethical principle of non-maleficence. Various studies have shown that physicians lack proper education in health economics, which makes navigation of this aspect of healthcare daunting. Finding a place for teaching economics and health policy has been difficult given the necessity to deliver a voluminous amount of scientific content during medical education. Nevertheless, physicians function as part of a healthcare industry that is not immune from the economic principles that govern commerce in any other service business. We suggest incorporation of customer service techniques from other business settings into the traditional practice of humanistic medicine in order to facilitate cost discussion and improve patient understanding. A physician's job is to educate the patient about potential plans of action to solve his/her problem, and costs represent key pieces of information for optimizing treatment plans. In the end, it is the patient who is entitled to decide what is best, or, in other words, the customer is always right.
\end{abstract}

\footnotetext{
ARTICLE

It is no secret that physicians are inadequately educated about healthcare economics. Various studies have demonstrated that physicians are consistently unaware of the costs their patients face from receiving care. ${ }^{12,3} \mathrm{In}$ fact, when specifically questioned about the cost of the care they provide, physicians have been found to substantially underestimate charges. ${ }^{4,5}$ Given the severe financial implications that medical bills can have on a patient's life, it is imperative that patients become aware of the costs of their decisions up front. A recent article by Rosenbaum and colleagues articulated the conundrum perfectly with the following scenario. " enough to climb the stairs to his apartment is meaningless if our care leaves him unable to afford that apartment. Protecting our patients from financial ruin is fundamental to doing no harm." ${ }^{\circ}$ By leaving patients in dire financial
}

situations, and in some cases bankruptcy, Rosenbaum and colleagues bring into question the ability of physicians to maintain adherence to the ethical principle of non-maleficence.

Although health care workers tend to prioritize health above all else, many patients may value saving money more than alleviating minor health concerns. ${ }^{8}$ Failing to discuss alternative treatment options in financial terms represents a great disservice to the patient. Ubel and colleagues equate the medical bills patients face to side effects, which are regularly disclosed and discussed with patients every day. ${ }^{8}$ Oftentimes, medical billing systems operate separately from practitioners, and, because of this, practitioners are ill equipped to counsel patients regarding the cost of services. ${ }^{1}$ Medical billing has become so complex that a start up company called Copatient has begun to provide medical bill interpretation services to decipher all of the different charges.? The company's website describes itself as a type of public accounting service for medical bills that on average saves customers $40 \%$ on their medical charges..$^{10}$ Certainly, there must be a way physicians can help simplify billing such that patients can navigate charges on their own. Before that can happen, however, physicians need to become better educated themselves about the economic environment in which they practice.

Finding a place for teaching economics to physicians has been difficult given the necessity to deliver a voluminous amount of scientific content during medical education. Still, medical school administrators are constantly seeking avenues to improve curricula. Health care expenditure comprised 17.9\% of GDP in 2011 in the United States, 11,12 and this percentage is only projected to rise. ${ }^{12,13}$ For this reason, educating the key decision makers in health care, including physicians, about the practical financial components of providing services becomes increasingly relevant. Hafferty and colleagues have proposed a training process that places economics first, before all other courses in medical school. ${ }^{1}$ Other suggestions include adding additional required competencies set forth by the Accreditation Council for Graduate Medical Education (ACGME) so that medical schools develop ways to teach cost-effective care. ${ }^{14}$ More direct interventions could take place at the clinical level by adapting electronic medical record systems to display cost information on the spot.15.16 Imagine a patient encounter where the physician can advise patients on the cost of laboratory studies or medication changes in real time. This would not only lead to cost consciousness by physicians, but also inform 


\section{The Medicine Forum, Vol. 17 [2016], Art. 20}

patients of what to expect in terms of costs to follow. Furthermore, patients have been found to choose more appropriate and less invasive procedures when offered open information. ${ }^{17}$ This type of price transparency is typical of service businesses in the United States, so why has medicine deviated from such a traditional customer service model?

The response from many in the medical field is that insurance complicates the financial aspects of health. However, medicine is not the only field in which insurance applies. Car insurance, renter's insurance, phone insurance, and a myriad of other types of insurance are all commonplace in the business world, and yet costs for repairs are quoted prior to taking action. Another explanation for non-traditional business practices in medicine is the perception that patients and customers are not the same. Medicine is not a typical service industry, but an enterprise in which personal connections supersede monetary ramifications. Due to the personal nature of healthcare, physicians feel like they provide a service that is more sacred than those provided in other industries. The goal of this article is not to undermine the importance of the patient-physician relationship in any way; the trust between a physician and patient is the keystone to good medicine. Nevertheless, physicians function as part of a healthcare industry that is not immune from the economic principles that govern commerce in any other service business.

Unfortunately, in the business context, many health care establishments fail to abide by many of the customer protection policies outlined by the Federal Trade Commission and Better Business Bureau. For example, a patient should be entitled to an accurate price quote prior to receiving treatment. Quoting prices is commonplace in some medical procedural settings, but the majority of patients in clinics or hospitals have no idea how much they will owe after their visit. This leaves many patients angry and burdened with an unforeseen bill after the fact. The financial implication of any course of treatment merits a place in the discussion between physician and patient prior to determining the final plan.

Many physicians fear thinking about treating patients in such a customer service mindset. Equating a patient to a customer seems to depersonalize the patient with the fear of eliminating the traditional physician-patient rapport. It should be possible, however, for physicians to maintain the art of personalized care, while concurrently providing excellent customer service. ${ }^{18}$ The two do not need to be mutually exclusive. ${ }^{18}$ Incorporation of customer service principles from other business settings into the traditional practice of humanistic medicine would likely achieve greater cost transparency and patient satisfaction. In fact, informing patients and letting them be active in their care has indeed been shown to improve health outcomes. ${ }^{17,19,20}$ In the end, the physician's job is to educate the patient about potential plans of action to solve his/her problem, and costs represent key factors for patients in order to choose an optimal treatment plan. Ultimately, it is the patient who is entitled to decide what is best, or, in other words, the customer is always right.

\section{REFERENCES}

1. Hafferty FW, Brennan M, Pawlina W. Professionalism, the invisible hand, and a necessary reconfiguration of medical education. Acad Med. 2011;86(11):e5.

2. Waugh JL. Education in medical billing benefits both neurology trainees and academic departments. Neurology. 2014;83(20):1856-61.

3. Cooke M. Cost consciousness in patient care--what is medical education's responsibility?. N Engl J Med. 2010;362(14):1253-5

4. Rock TA, Xiao R, Fieldston E. General pediatric attending physicians' and residents' knowledge of inpatient hospital finances. Pediatrics. 2013;131(6):1072-80

5. Portale JV, Harper LJ, Fields JM. Emergency physicians' knowledge of the total charges of medical care. Am J Emerg Med. 2013;31(6):950-2.

6. Rosenbaum L, Lamas D. Cents and sensitivity--teaching physicians to think about costs. N Engl J Med. 2012;367(2):99-101.

7. Himmelstein DU, Thorne D, Warren E, Woolhandler S. Medical bankruptcy in the United States, 2007: results of a national study. Am J Med. 2009;122(8):741-6

8. Ubel PA, Abernethy AP, Zafar SY. Full disclosure--out-of-pocket costs as side effects. N Engl J Med. 2013;369(16):1484-6.

9. Row, D.K. "Portland Startup CoPatient Navigates Complex Medical Billing for Consumers." Oregonlive. The Oregonian, 5 Nov. 2012. Web. 11 Oct. 2015.

10. CoPatient. https://www.copatient.com/. Web. Accessed 4 Dec. 2015.

11. Aldridge MD, Kelley AS. The Myth Regarding the High Cost of End-of-Life Care. Am J Public Health. 2015;105(12):2411-5

12. Moses H, Matheson DH, Dorsey ER, George BP, Sadoff D, Yoshimura S. The anatomy of health care in the United States. JAMA. 2013;310(18):1947-63.

13. Emanuel EJ. Where are the health care cost savings?. JAMA. 2012;307(1):39-40.

14. Weinberger SE. Providing high-value, cost-conscious care: a critical seventh general competency for physicians. Ann Intern Med. 2011;155(6):386-8

15. Patel MS, Volpp KG. Leveraging insights from behavioral economics to increase the value of health-care service provision. J Gen Intern Med. 2012;27(11):1544-7.

16. Brook RH. Do physicians need a "shopping cart" for health care services? JAMA. 2012;307(8):791-2.

17. Gann B, Grant MJ. From NHS Choices to the integrated customer service platform. Health Info Libr J. 2013:30(1):1-3.

18. $\mathrm{Ho} \mathrm{CH}$. Developing practical wisdom in customer service. Acad Med 2015:90(4):398

19. O'connor AM, Bennett CL, Stacey D, et al. Decision aids for people facing health treatment or screening decisions. Cochrane Database Syst Rev. 2009;(3):CD001431

20. Coulter A, Collins A. Making shared decision-making a reality. No decision about me, without me. The King's Fund. 2011. 